\title{
Comment on a recent genetic study on the risk profile of Hirschsprung's disease from a pediatric surgeon's perspective
}

\author{
Nana Nakazawa-Tanaka ${ }^{1,2}$, Geoffrey J. Lane ${ }^{2}$, Atsuyuki Yamataka ${ }^{2}$ \\ ${ }^{1}$ Department of Pediatric Surgery, Juntendo University Nerima Hospital, Tokyo, Japan; ${ }^{2}$ Department of Pediatric General and Urogenital Surgery, \\ Juntendo University School of Medicine, Tokyo, Japan \\ Correspondence to: Atsuyuki Yamataka. Professor and Head, Department of Pediatric General and Urogenital Surgery, Juntendo University School of \\ Medicine, 2-1-1 Hongo, Bunkyo-ku, Tokyo 113-8431, Japan. Email: yama@juntendo.ac.jp. \\ Comment on: Tilghman JM, Ling AY, Turner TN, et al. Molecular Genetic Anatomy and Risk Profile of Hirschsprung's Disease. N Engl J Med \\ 2019;380:1421-32.
}

Submitted Feb 25, 2020. Accepted for publication Apr 17, 2020.

doi: $10.21037 /$ atm-20-1933

View this article at: http://dx.doi.org/10.21037/atm-20-1933

Hirschsprung's disease (HD) is a congenital disorder, defined by absence of the neuronal ganglion cells in a portion of the intestinal tract, usually the distal colon, because enteric neural crest cells fail to migrate completely during intestinal development. The incidence of this disorder is estimated to be 1 in 5,000 live births.

The majority of HD patients present with short segment aganglionosis and the clinical outcome of these patients is favorable (1). On the other hand, total intestinal aganglionosis, the most severe type of $\mathrm{HD}$, is life-threatening and the clinical outcome is totally different (2-4).

Clinically, we pediatric surgeons are often asked by the parents of an affected child whether the patient's siblings or offspring may have an increased risk for developing the same condition. A genetic study by Tilghman et al. may provide some evidence (5). They suspected that, multiple genetic risk factors individually contribute to increasing the risk for developing HD. The authors demonstrated that, HD has a complex suite of risk variants, ranging from common non-coding variants to rare coding variants and copy number variants. They mention that at least one identifiable genetic risk factors can be identified in approximately $72 \%$ of $\mathrm{HD}$ cases and approximately $21 \%$ of patients have multiple risk factors, with the genotypespecific incidence increasing by a factor of more than 100 (risk ranging from approximately 1 in 18,800 to 1 in 120) as the number of genotypic risk factors increases from zero to three. That is, the estimated risk of HD for a fetus with no identifiable risk factors is only 1 in 18,800 whereas that for a fetus with the most extreme genetic risk profile is 1 in 120 , which is still not very high but much higher than the estimated incidence of HD in general. Such information is meaningful and useful for genetic counseling. However, we suggest that genetic counseling should be conducted carefully since the estimated risk mentioned earlier is overall and the authors did not find any significant genotypephenotype associations with respect to segment length or additional anomalies.

The authors of the study we are commenting on state their primary purpose as being to enable genetic stratification of patients in order to determine how genetic susceptibility manifests in clinical disease and its penetrance. They suggest that such genetic stratification could be used to determine whether postoperative bowel function $(\mathrm{POBF})$ is related to genotype. There are several studies in the literature that investigate whether surgery itself might have some detrimental effect on postoperative outcome. For instance, we investigated whether the starting point of rectal mucosal dissection in preparation for transanal pull-through might affect POBF in HD patients. We conducted a medium-term prospective comparison of bowel function between patients who had rectal mucosal dissection commencing on the anorectal line with patients who had dissection commencing above the dentate line (6,7). From this study we found that medium-term bowel function is better when the anorectal line is used, thus, we recommended that the anorectal line should be the landmark for rectal 
mucosal dissection during transanal pull-through for HD (7). This conclusion is also in keeping with the findings of another one of our studies on intestinal innervation where we found strong evidence for the anorectal line to be the best landmark to ensure successful outcome of transanal pull-through by proving that the squamous-columnar epithelial junction is equivalent to the anorectal line and that the anorectal line represents the upper edge of the anal transition zone, as well as being the end-point of the enteric nervous system (8). The mechanism for good POBF can be readily appreciated and the importance of the anorectal line as an anatomic landmark cannot be overemphasized. Thus, dissection of the aganglionic layer without injuring the anorectal line and an intact anal transition zone would seem to be crucial for normal defecation in HD cases. It would be very interesting to review the operative records of each of the HD patients in the study we are commenting on to confirm histopathology results and surgical techniques used because POBF will be affected directly by surgical technique. Similarly, it would also be interesting to investigate our HD cases with problematic POBF using genetic assessment techniques to confirm the presence of any genetic disposition to poor POBF. Since all patients diagnosed with HD usually undergo surgery to remove the aganglionic segment, except for some rare cases such as total intestinal aganglionosis, it is very difficult to evaluate potential risks for POBF without taking into account the influence of surgery itself. However, if a patient with HD can be treated without conventional surgery, or if HD can be prevented by advancements in genetic research, things would be different, especially for more life-threatening conditions, such as total intestinal aganglionosis; prevention will be most meaningful.

In recent years, HD research has focused on stem/ progenitor cells and cell therapy as a potential attractive option for treating HD $(9,10)$. Genetic manipulation is another option for future therapy. Although HD is not a monogenic disease, recent advancement in gene editing systems has enabled gene-mutations associated with HD that influence neuronal cell proliferation, migration, and differentiation to be corrected. The capacity of enteric neural crest cells for migration and differentiation was restored in vitro after gene manipulation (11).

Although there are significant challenging processes and ethical issues to be discussed before clinical application, the genetic findings obtained in the study we are commenting on will undoubtedly influence the direction of further research into the future of treating $\mathrm{HD}$, the etiology of $\mathrm{HD}$, and possibly its prevention.

\section{Acknowledgments}

Funding: None.

\section{Footnote}

Provenance and Peer Review: This article was commissioned and reviewed by the Academic Editor Wei Liu, PhD (Department of Gastroenterology of Yichang Central People's Hospital. Institute of Digestive Disease, China Three Gorges University, Yichang, China).

Conflicts of Interest: All authors have completed the ICMJE uniform disclosure form (available at http://dx.doi. org/10.21037/atm-20-1933). The authors have no conflicts of interest to declare.

Ethical Statement: The authors are accountable for their comments about the original paper only. Questions related to the accuracy and integrity of the original paper should be appropriately investigated and resolved with the original authors.

Open Access Statement: This is an Open Access article distributed in accordance with the Creative Commons Attribution-NonCommercial-NoDerivs 4.0 International License (CC BY-NC-ND 4.0), which permits the noncommercial replication and distribution of the article with the strict proviso that no changes or edits are made and the original work is properly cited (including links to both the formal publication through the relevant DOI and the license). See: https://creativecommons.org/licenses/by-nc-nd/4.0/.

\section{References}

1. Meinds RJ, van der Steeg AFW, Sloots CEJ, et al. Longterm functional outcomes and quality of life in patients with Hirschsprung's disease. Br J Surg 2019:106:499-507.

2. Ruttenstock E, Puri P. A meta-analysis of clinical outcome in patients with total intestinal aganglionosis. Pediatr Surg Int 2009:25:833-9.

3. Obata S, Ieiri S, Akiyama T, et al. Nationwide survey of outcome in patients with extensive aganglionosis in Japan. Pediatr Surg Int 2019:35:547-50.

4. Laughlin DM, Friedmacher F, Puri P. Total colonic aganglionosis: a systematic review and meta-analysis 
of long-term clinical outcome. Pediatr Surg Int 2012;28:773-9.

5. Tilghman JM, Ling AY, Turner TN, et al. Molecular Genetic Anatomy and Risk Profile of Hirschsprung's Disease. N Engl J Med 2019;380:1421-32.

6. Yamataka A, Kaneyama K, Fujiwara N, et al. Rectal mucosal dissection during transanal pull-through for Hirschsprung's disease: the anorectal or the dentate line? J Pediatr Surg 2009;44:266-9.

7. Miyano G, Koga H, Okawada M, et al. Rectal mucosal dissection commencing directly on the anorectal line versus commencing above the dentate line in laparoscopyassisted transanal pull-through for Hirschsprung's disease: Prospective medium-term follow-up. J Pediatr Surg 2015;50:2041-3.

8. Takeda M, Miyahara K, Akazawa C, et al. Sensory

Cite this article as: Nakazawa-Tanaka N, Lane GJ, Yamataka A. Comment on a recent genetic study on the risk profile of Hirschsprung's disease from a pediatric surgeon's perspective. Ann Transl Med 2020;8(19):1258. doi: 10.21037/ atm-20-1933 innervation of the anal canal and anorectal line in Hirschsprung's disease: histological evidence from mouse models. Pediatr Surg Int 2017;33:883-6.

9. Wilkinson DJ, Bethell GS, Shukla R, et al. Isolation of enteric nervous system progenitor cells from the aganglionic gut of patients with Hirschsprung's disease. PLoS One 2015;10:e0125724.

10. Cooper JE, McCann CJ, Natarajan D, et al. In vivo transplantation of enteric neural crest cells into mouse gut; engraftment, functional integration and long-term safety. PLoS One 2016;11:e0147989.

11. Lai FP, Lau ST, Wong JK, et al. Correction of Hirschsprung-associated mutations in human induced pluripotent stem cells via clustered regularly interspaced short palindromic repeats/as 9 , restores neural crest cell function. Gastroenterology 2017;153:139-53.e8. 